\title{
1. The promise, application and pitfalls of big data
}

\section{John Storm Pedersen and Adrian Wilkinson}

\section{INTRODUCTION}

Digital society is upon us (Lupton, 2015), and appears to have established a position in the zeitgeist of modern society. Digital society has emerged from and is expected to develop further via digitizing, big data, big data analytics, automatically logging almost all human activities and decisions made in information and communication technologies (ICT), access to online information in almost real time, artificial intelligence (AI), data-informed decision-making processes and data-driven management (Pedersen and Wilkinson, 2018).

According to the contributions in this book, which are all research based, big data analytics is considered the core of the digital society. Big data analytics is a source of knowledge that creates significantly new opportunities to mobilize and allocate individuals', organizations' and societies' resources more efficiently. The proponents of big data analytics promise that it is the key to making the world a better place to live in. Hospitals can treat more patients and better (Chapters 9 and 10); schools can become more efficient public institutions and pupils can attain greater well-being and higher achievements (Chapter 13); big cities can become a better place to live in (Chapter 7); green energy can be developed further and become cheaper due to smart logistics (Chapter 5); public administration can become more customized and efficient (Chapter 9); and women and men can become superwomen and supermen by turning into cyborgs via wearables (Chapter 2).

The driver behind big data analytics is the promise that the individuals, organizations and states that exploit it best will become winners. Individuals who accept wearables to become a kind of cyborg can significantly increase their physical and intellectual performances. Organizations, whether private or public, that opt for data-driven management based on big data analytics will perform better than their rivals. States that support citizens, organizations and state institutions to master big data analytics 
will become the winners of the global competition among nations. However, many contributions in this book show the difficulty of applying big data analytics in practice. See Chapters 3, 4, 11, 12, 13 and 18.

This begs this question: are data analysts as the masters of big data analytics, or (semi-)professionals and middle managers as the masters of the daily operations in public and private organizations, the best at decision making and allocation of resources? Based on the contributions in this book, it is impossible to provide a clear-cut answer. To determine whether human or machine is best, we need to test human versus machine in decision making and allocation of resources. This ought to become an important research field in the years to come.

Our position, based on this book's contributions, is that managers will support the application of big data analytics and related management tools such as data-driven decision-making processes and data-driven management. The question is: why?

Most managers are confronted with a gap between what they would like and what they have regarding organizational performance. This gap creates a sociopsychological anxiety or cognitive dissonance combined with a permanent openness towards organizational change (Festinger, 1957; Brunsson, 2009, p. 1). In addition, managers wish to be seen as complying with the prevailing norms of rationality and progressiveness, and they can do so efficiently by adopting the latest management fashion (Abrahamson and Fairchild, 1999), which can be considered super-recipes/ super-standards/master-ideas (Røvik, 2002; Røvik and Pettersen, 2014). These are new worldwide concepts that offer both diagnoses of and solutions to important managerial challenges. A related argument is that managers follow 'high-fashion' organizations (Marchington et al., 1993) or their own self-interest, driven by macro-level 'management fashions' (Wilkinson and Mowbray, 2019). Given this, big data analytics offers the ultimate modern version of the classic model of rational decision making, which has an almost mythological position as the best possible decisionmaking model (March, 1995, p. 12; 1998). As shown directly and indirectly through many contributions in this book, data-driven management also offers the cutting edge of modern management - the present 'fashion' of management (Wilkinson, Armstrong and Lounsbury, 2017).

Big data analytics also fits nicely with the notion of evidence-based management (Morrell and Learmouth, 2017), which is currently in high demand among managers to make (semi-)professionals and experts accountable. The idea of evidence-based management is to incorporate the use of the best available scientific evidence from peer-reviewed sources and the systematic gathering of organizational facts, indicators and metrics to better act on the evidence and practitioner judgement, assisted 
by procedures, practices and frameworks that reduce bias, improve decision quality and create more valid learning over time. In evidence-based management, decisions are made explicit to reduce decision neglect (not making a decision that needs to be made), to avoid making decisions on auto-pilot (important actions taken without deliberation) and to increase mindful, deliberate decision making. The process of making decisions explicit comprises two parts. The first aspect is developing decision awareness, recognizing the numerous micro-choices made every day, all with the potential to be informed by evidence. The second feature of making decisions explicit involves beginning to pay attention to how a decision is made, with whom and with what evidence (Rousseau and Barends, 2011). This is what data analytics and data-driven management are about (see Chapter 10).

However, data analytics and data-driven management are not the solution to everything. Seen from the perspective of employees, data analytics combined with data-driven management can be seen as sophisticated control management. Within data-driven management, based on big data analytics, all aspects of the employees' performances are known, right down to the individual. Managers can use this type of knowledge to control employees, categorize employees as high and low performers, and deselect the low performers over time (see Chapter 4 on human resource management and Chapter 10 on data-driven management). Big data analytics and data-driven management consequently evoke conflicts between employees and managers, which must be settled before the benefits of big data analytics and data-driven management can be harvested.

A new logic emerges from big data analytics, data-driven decisionmaking processes and data-driven management: the logic of data; that is, that data, not humans, can tell which decisions are best, and consequently which allocation of given resources is optimal. The more the logic of data is promoted and developed within digital society, the more likely it is that the logic of data turns into an institutionalized logic, which we term 'dataism'. To the proponents of big data analytics, data-driven decision-making processes and data-driven management, dataism is superior to other logics in society and therefore has the potential to crowd these out. However, history tells us (Thornton, Ocasio and Lounsbury, 2012) that a new logic such as dataism cannot crowd out all other logics within society. Normally a new (emerging) logic will be combined with society's existing logics. This issue will be discussed again at the end of this introduction because combinations of logics matter.

In our book, research-based chapters from authors from many disciplines and from across the globe provide an evidence base beyond the gurus' and consultants' descriptions of promising cases and prescriptions 
for application. Our authors are experts in their fields and were not chosen because they have a specific stance on digital society, but because they provide academic and critical perspectives.

Our introduction is organized into three sections around the promise, application and pitfalls of big data, followed by some reflection on the logic of data: dataism.

\section{PROMISE}

The promises of big data analytics and the related tools presented, discussed and analysed in this book are summarized in the following ten categories of promise. The categories begin with specific promises and end with complex and abstract promises.

\section{Digital Selection Tools}

According to this book's contributions, big data analytics and related tools make it possible to evaluate performances in almost real time, within and among private and public organizations. The performances of employees, experts, managers, units and departments within organizations can be calculated based on agreed key performance indicators and ranked accordingly. Private and public organizations can also be ranked based on key performance indicators. The ranking of performances is a tool to reveal high and low performers. The promise is to refine ranking of all forms of performance. That is, to refine digital tools to deselect low performers with the aim of increasing (overall) performances.

\section{Increase Efficiency - in the Daily Operations}

Digital tools to improve efficiency in the daily operations are invented and deployed based on big data analytics. AI can make recruitment of people faster and cheaper and digital tools can substitute for people within human resource management (HRM) departments in the initial screening process of applicants (see Schlotz, Chapter 4). The algorithms built into ICT can make frontline work in administration faster and cheaper. The time required for citizens/customers requesting counselling, reporting on decisions made and organizing follow-up activities on counselling can be reduced significantly. As a result, human resources are freed up in frontline work. This creates opportunities (for managers) to deploy more human resources in (creative) core activities. The development of digital tools rooted in big data analytics, which is driven by cost reductions in the daily 
operations, also results in automation of routine tasks, and consequently, routine jobs. This changes the framework of conditions for jobs in both private and public organizations in terms of the jobs offered and the skills required to secure jobs. Cases from administration (Chapter 8), HRM (Chapter 4), childcare (Chapter 11), education (Chapter 13), health (Chapter 10) and other fields are provided in this book, as well as more general analyses and discussions. The provided cases present different tools, phases in the development of the tools and conflicts related to the tools. Finally, the promises of how the tools' potentials may be exploited in the future are presented and discussed.

\section{Quality - Welfare Services}

Big data analytics supports improvements in the quality of welfare services in many fields. These include improvements in predictive risk modelling in childcare, improvements in the administration of pension schemes in terms of speed, improvements in self-services to facilitate citizens' access to services, and improvements in data-driven management in healthcare to meet patients' needs. 'Smart cities' represent an advanced case of improvements of welfare services - for instance, improvements in the quality of life of residents in big cities on parameters such as improved infrastructures, mass transit systems, energy consumption (meaning less air pollution), and recycling of garbage (meaning less plastic pollution). However, it is a complex process to establish smart cities because several stakeholders must come together and agree on huge investments, regulations and, very importantly, ownership of the data involved in the creation of smart cities (see Löfgren and Webster, Chapter 7).

At the level of society, big data analytics supports achieving sustainability in relation to energy consumption (see Bonev and Söderberg, Chapter 5). The book provides many cases of efforts to improve welfare services, coming from many different fields (see Breit et al., Chapter 8; Pedersen, Chapter 10; Lyneborg, Chapter 11 and Gillingham, Chapter 12).

\section{Learning - Digital Feedback Loops}

Feedback loops are an important integrated element in big data analytics and related tools, as shown in this book. They provide new and cheap learning possibilities for service semi-professionals, experts and managers. The feedback loops within big data analytics make it possible to calculate the ratios of the predicted effects of decisions and the actual effects of these - for example, social workers in a job centre deciding to provide longterm unemployed citizens with additional services to enable them to have 
a better chance of success in the job market. Feedback loops can inform social workers whether more long-term unemployed citizens than normal are back in jobs after six months. Another example is managers at hospitals deciding to implement data-driven management to better meet some key performance indicators. Feedback loops can inform managers whether the key performance indicators have improved over a specific time period. Given this, feedback loops can increase service (semi-)professionals', experts' and managers' capabilities in predicting the ratios of the anticipated effects of decisions and their actual impact. This is important, because service (semi-)professionals, experts and managers believe (for good reasons) that they can do better than statistics portray (Kahneman and Klein, 2009; Kahneman, 2011) (see also Pedersen, Chapters 10 and 15 this volume). Several contributions in this book outline the issue of learning based on digitized feedback loops.

\section{Evidence-based Provision of Welfare Services}

When combined with ICT, the feedback loops within big data analytics mentioned above have the potential to pave the way for evidence-based provision of welfare services in many fields such as teaching, social work, health and smart cities. Almost all activities, decisions, events and costs are logged and stored automatically in ICT systems in almost all organizations, in all sectors, whether private or public. This allows organizations to describe and define the provided services in detail. This, combined with information about the effects of the provided services on the clients' welfare based on digitalized feedback loops, makes it possible to calculate ratios of provided welfare services/effects of provided services. Because the costs of provided services can typically be found in an organization's ICT, it is also possible to calculate the cost-effectiveness of provided services. In other words, it is, in principle, possible to make service (semi-)professionals, experts and managers continuously accountable. However, as shown in some of this book's contributions, this is a promise that will be (very) hard to fulfil (see also the 'Application' section of this chapter).

\section{Politics - the 'Bad' Versus the 'Good' Guys!}

A new digital tool in political campaigns has been developed based on big data analytics and micro-marketing, particularly in the USA. Aagaard (Chapter 16) presents and analyses this new digital tool. The promise of this new tool is to win elections. The tool draws on methods known from military psychological operations (among others), which includes disinformation and fake news, and manipulation of attitudes and sentiments. 
The tool is especially designed to target highly segmented groups of voters, donors and supporters with the aim of achieving 'informational dominance', and by doing so, win elections.

In relation to political campaigns and more generally, disinformation and fake news beg to be detected, revealed and combatted. Again, big data analytics is helpful; in this case, because it enables the invention of software programs that can be deployed to detect and reveal disinformation and fake news. In other words, there is a digital 'war'. The 'bad' guys design and disseminate disinformation and fake news and the 'good' guys track and combat disinformation and fake news before citizens are 'hit'. Nguyen and Stantic (Chapter 17) examine the topic of rumour detection in social media and how it is possible to detect disinformation and fake news.

\section{Cyborg - Superwomen and Supermen!}

Big data analytics combined with digital wearables promise to empower people significantly. By combining big data analytics and digital wearables, it is possible to create a cyborg. Here, Estivill-Castro (Chapter 2) describes a cyborg as a 'human whose abilities are expanded beyond natural limitation by artificial elements built into the body'. In other words, a cyborg makes it possible for humans to perform (far) beyond their natural physical and intellectual capabilities by digitalizing humans' bodies and selves to a degree where the bodies and selves are no longer private (Lupton, 2015). This raises the question: do humans themselves program their bodies and selves to perform beyond natural limitation or are humans programmed by AI? The answers to this question vary in the book's contributions, depending on the mix of humans and artificial elements built into their bodies.

\section{Winners - Private and Public Organizations}

The key driver of big data analytics and related tools is the promise that the potential embedded in the seven promises presented above creates winners - see Mikalef, Chapter 3. The firms that best exploit the potential - via big data analytics - embedded in the promises will achieve the cutting edge over their business rivals and become winners.

Public organizations that best exploit the potential embedded in the mentioned promises become winners too, albeit it in a different way. In modern welfare states, public organizations are permanently squeezed between the citizens' demand for welfare services and the same citizens' lack of willingness/possibilities to pay taxes that fully cover the costs of the provision of the requested welfare services (Winter and Mouritzen, 
2001, p. 109; Pedersen, 2010). The public organizations that best deal with this squeeze based on big data analytics and related tools therefore become winners in the welfare states. The potential embedded in the seven promises of big data analytics and related tools above are presented, discussed and analysed from different perspectives in this book.

\section{The Rational Decision-making Model Digitalized}

Big data analytics and the related tools hold the promise of making the best decision-making model, and consequently, the most optimal allocation of resources possible. According to March (1998), the rational decisionmaking model has an almost mythological position as the best possible decision-making model. The model is defined as '(1) a set of alternatives, (2) the alternatives have different future consequences, (3) the future consequences are calculated on the basis of a set of preferences, and (4) the chosen alternative is characterized by having the best consequences given the preferences' (March, 1995, p. 12). Because this model of decision making is believed to be the best, organizations and humans who do not exercise this model are the future losers due to a non-optimal allocation of resources (March, 1995, p. 13; 1998). That is, organizations and humans become low performers to be deselected in the competition among organizations and humans. This deselection can be avoided if humans and organizations opt for the revitalized version of the classic model of rational decision making.

\section{The Logic of Data - Dataism!}

From big data analytics - data-driven decision-making processes and datadriven management - a new logic emerges: the logic of data, as previously mentioned; that is, that data, not humans, can tell which decisions are best, and consequently, which allocation of given resources is optimal. This belief in the logic of data, we term 'dataism'.

Analysed within the meta-theory of the institutional logics perspective (Thornton et al., 2012), dataism has the potential to evolve into an institutional order within the interinstitutional system of ideal types that consists of market, community, corporation, family, religion, state and profession (Thornton et al., 2012, p. 73). In this book, dataism's potential to evolve into an institutional order is not analysed and discussed in detail. By drawing on the institutional logics perspective, the point to be made here is that no institutional order - logic - can fully dominate other institutional orders - logics - in society. Institutional orders are always combined within society, organizations and individuals. It is therefore unlikely that dataism will come to dominate fully in society, organizations and individuals in 
the future. It is more likely that dataism will achieve a position in society, organizations and individuals as one of several institutional orders. In fact, it is most likely that dataism will enter into a 'symbiotic co-existence' and 'symbiotic co-evolution' (Van Buuren, Gerrits and Marks, 2009, p. 158) with other institutional orders - logics.

However, 'symbiotic co-existence' and 'symbiotic co-evolution' do not signal the end of conflicts. All combinations of institutionalized logics involve conflicts, overlap and competition according to the institutional logics perspective (see also Pedersen and Wilkinson, 2018 and Baruchello, Chapter 18 in this book). Consequently, dataism will be modified by other logics.

Dataism is analysed and discussed further in the 'Pitfalls' section of this chapter.

\section{APPLICATION}

Many cases in this book describe and analyse how big data analytics and related tools have been put into practice. These cases can be placed on a continuum. On the one end, we find success stories (see Chapter 9 on services and administration and Chapter 10 on data-driven management for examples); at the other end, we see failure (see Chapter 12 on digital assessment tools and Chapter 14 on education for examples).

According to the contributions in this book, the most important applications required are summarized in the six categories presented below. The categories begin with the struggle to tap values from big data based on big data analytics and end with an analysis of data analysts as a group of privileged professionals who are to be held accountable like other professional groups.

Before presenting the six categories of the most needed applications, it is worth mentioning that application is not just a matter of applying more advanced technologies and techniques. As Löfgren and Webster write in Chapter 7, referring to Batty (2012) on smart cities, 'cities only become smart when people are smart'.

\section{The Struggle to Tap Value from Big Data - Based on Big Data Analytics}

According to the contributions in this book, firms and public organizations struggle to tap value from big data based on big data analytics and related tools. To tap (more) value from big data, application of big data governance/big data analytics capabilities within firms and public organizations is required. Chapter 3 by Mikalef focuses on this very issue. 
In other chapters, the issue is discussed within specific contexts such as energy management (Chapter 5), tourism (Chapter 6), healthcare (Chapter 9), political communication (Chapter 16), school management (Chapter 13) and smart cities (Chapter 7).

\section{Testing Digital Tools Against Human Knowledge}

Do digital tools such as digital assessment tools, data-driven management, digital micro-marketing and self-service perform sufficiently or are applications required? It is impossible to give a clear-cut answer to this question. Why? This is because neither the tools' promised potentials nor the criteria the tools must meet to become a success are typically defined clearly.

In addition, as shown in this book, digital tools in general are far from 100 per cent correct when it comes to predictions, and thus optimal decision making and resource allocation. Welfare service semi-professionals (Pedersen and Wilkinson, 2018) and experts (Kahneman and Klein, 2009; Kahneman, 2011) are also far from 100 per cent when it comes to predictions, and thus optimal decision making and resource allocation. Given this, in many cases, it is uncertain whether digital tools rooted in big data analytics or welfare service semi-professionals', experts' and managers' judgements rooted in personal experiences, intuition and tacit knowledge are best when it comes to the 'package' of predicting, decision making and allocation of resources.

Therefore, testing digital tools' capabilities in predicting, decision making and allocation of resources against professionals', experts' and managers' capabilities is required to answer whether digital tools perform better (create more value) than humans.

\section{Digital Tools, Tacit Knowledge, Control, Trust and Legitimacy}

Data analysts' digital tools and welfare service semi-professionals' knowledge are not a perfect match (Pedersen and Wilkinson, 2018). Among other issues, it is (very) difficult to transform service professionals' tacit knowledge into bits and bytes to feed digital assessment, recruitment and prediction tools.

Even when administrative digital tools in the form of ICT work successfully, according to welfare service semi-professionals, professionals create workarounds. The main reason for this is that what the professionals themselves consider important knowledge in specific cases is excluded from the administrative ICT. To compensate for this, the professionals create workarounds within ICT to circulate and share knowledge that the professionals themselves deem important in order to process specific cases. 
This is often in the form of special notes, recommendations, a description of the issues in cases via narratives, and so on (see Chapters 11 and 12).

For some other welfare service semi-professionals, digital assessment tools and prediction tools simply exclude too much of the professionals' tacit knowledge. That is, the tools ignore too much of the circulation of knowledge that the professionals deem important to do their jobs. In such cases, semi-professionals simply do not trust the digital tools, which consequently lose legitimacy - see Chapters 12 and 13. This has several implications. One is that digital tools do not support the evidence-based provision of welfare services, which for the proponents of digital tools is considered a key feature of digital tools. Another is that semi-professionals do not deploy digital feedback loops as an opportunity to learn about the ratios of provided welfare services/effects of provided services.

Seen from the perspective of employees and middle managers, digital tools can be viewed as control tools. Tracking, recording and ranking employees' and middle managers' performances on many variables are integrated elements and key elements in data-driven management (see Chapters 4 and 10). Low versus high performers, compliance to internal and external quality standards and policies, absence from work, and much more are tracked, recorded and ranked almost in real time as part of data-driven management and digitalized HRM. Ranking can also be used as criteria in job promotion, wage level and the design of work standards, procedures, and so on. In other words, digital tools make it easy - intentionally or not - to control and deselect employees. Because of these features, digital tools tend to create scepticism, mistrust and resistance among both employees and middle managers in many private and public organizations.

In summary, it is safe to conclude that application is required in two areas. First, application is required to better integrate professionals' and middle managers' tacit knowledge into digital tools with the aim of having professionals and middle managers trust digital tools in daily operations. Second, application is required to set up standards for how digitizing tools are deployed, directly and indirectly. Who controls the application of digital tools? Is it a tool to aid these employees in their work or a tool to control them?

\section{Algorithmic Power and Accountability}

Algorithms are powerful. They are deployed to "shape and define concepts of "dangerous", "safe", "unhealthy", "risky", "under-achieving", "productive" and so on, thus producing concepts and reproducing new forms of values' (Lupton, 2015, p. 103). Algorithms produce and reproduce values for being normal/abnormal, good/bad for society, valuable/not valuable 
for organizations, good/bad for business, and of interest/not of interest for political campaigns. Individuals who are categorized as having an unhealthy lifestyle, being bad for business, of no interest for political campaigns, and so on, secretly end up in invisible algorithmic prisons (Davidow, 2014).

Furthermore, when individuals are categorized, decisions about and allocation of resources follow. Algorithms built into digital assessment tools categorize families and children as being vulnerable/not vulnerable. Based on this categorization, decisions are made to help/not help the families and children; that is, whether to allocate relatively huge resources to the families and children in terms of social benefits, rehabilitation, mentors and other forms of support (see Chapters 11 and 12 for cases of algorithmic power in social assessments).

Algorithms are not neutral (Lupton, 2015), nor do they reflect objective neutrality (see Chapters 7 and 18). Algorithms reflect the questions asked by someone and data are collected to answer those questions. In other words, individuals' and organizations' questions, preferences, choices, access to data, skills, and more, are always reflected in algorithms. Because of this, algorithms cannot be held responsible for the consequences of the above-mentioned categorization of individuals, algorithmic prisons, decision making and allocation of resources. Self-driving cars have no standing; only individuals have standing. Consequently, the individuals who install the algorithms in self-driving cars are responsible for the cars' driving (see Chapter 2 for an interesting discussion of this issue).

With reference to the United States Association for Computing Machinery (USACM, 2017) and Binns (2017), in Chapter 12, Gillingham suggests how algorithmic responsibility can be addressed through seven principles: (1) awareness; (2) access; (3) agency responsibility; (4) explanation; (5) provenance; (6) auditability; and (7) validation and testing.

\section{Equality and Big Data Literacy}

In digital society, equality is primarily seen as a matter of the citizens' access to the Internet. If some (groups of) citizens have limited access to the Internet due to poor digital infrastructures, lack of IT skills and lack of income, inequality among citizens increases. To avoid this, states must provide digital infrastructures of good quality, access to the Internet and education in IT skills.

Furthermore, new norms and standards regarding access to digital tools, which give the citizens fair and just access to relevant digitals tools, must be developed and implemented. This is access to one's own digital record in healthcare and education, access to one's own digital record in HRM, and access to one's own digital record in insurance companies, and so on. 
However, it is one thing to have access to digital infrastructures of good quality and the Internet, access to digital tools, achieving algorithmic accountability, and so on. It is quite another to understand and be able to communicate about digital algorithms and digital tools, and to interpret digital track records in healthcare and education. Big data literacy is therefore required.

In Chapter 4, Scholz analyses and discusses big data literacy related to HRM. The core of big data literacy is the ability and skills to understand and communicate about big data analytics and related tools. Drawing on D'Ignazio and Bhargava (2015, p. 2), big data literacy is defined as:

- Identifying when and where data is being collected.

- Understanding the algorithmic manipulations.

- Weighing the real and potential ethical impacts.

By referring to this quote, and under these three headings: (1) computational thinking; (2) statistical thinking; and (3) sceptical thinking, Scholz elaborates on the importance and benefits of big data literacy (see Chapter 4).

Almost by definition, big data literacy is not only important in HRM but also in most other areas in digital society. Moreover, given the importance of big data analytics and related tools within digital society, the state should be active in promoting big data literacy in firms, public organizations and in society in general.

\section{Data Analysts - a Privileged Profession and a Scarce Resource}

Data analysts are the masters of the key tool within digital society: algorithms. This makes data analysts privileged professionals, in the sense that data analysts formulate the questions to be answered by computers on behalf of others (citizens, managers, firms, public organizations, and others), invent and implement the algorithms to program computers to answer the questions asked, interpret the answers given by the computers, and pass their interpretations of the computers' answers on to the persons or organizations that originally asked the questions to be answered. Due to this position, data analysts are in high demand. For example, the demand for data analysts in energy firms increased by a factor of ten from 2016 to 2017 (see Chapter 5). As shown in several contributions in this book, data analysts are a scarce resource. This may be why data analysts are said to have the 'sexiest job in the 21st century' (Davenport and Patil, 2012).

Because data analysts hold key positions in digital society, it is expected that the previously mentioned trend to hold professionals and experts 
more accountable will also apply to data analysts. This book provides many good reasons to hold data analysts (and their managers) accountable. Among these is that data analysts offer many tools to increase other professionals' and experts' accountability, including tools to provide evidence-based services. Given this, it is very likely that other professionals, top managers, politicians and citizens find it appropriate to require that data analysts demonstrate how accountability and evidence-based provision of services are best performed.

\section{PITFALLS}

According to the contributions in this book, pitfalls are related to: (1) application; (2) algorithmic responsibility and accountability; (3) 'democratization' and democracy; and (4) dataism.

\section{Application - Routes to Partial Failure and the Human Factor}

To get big data analytics and related tools to work in practice, some of the required applications seem almost impossible to achieve. It is difficult to get digital assessment tools in social policy and in the administration of social welfare services to work properly due to (very) low data quality and failure to integrate social workers' tacit knowledge and secret algorithms. As a result, the tools are not trusted and have therefore lost legitimacy (see Chapters 11 and 12 for a discussion of this issue).

In addition, according to almost all of the contributions in this book, humans are still required to supervise big data analytics and decision making and allocation of resources on the basis of tools related to big data analytics. 'Old' and 'new' models and tools for processing data, decision making and resource allocation must be combined for the coming years.

It is safe to conclude that it will take years to get big data analytics and related tools to work sufficiently to create trust in and legitimacy of digital tools in some fields. Conflicts related to control, and accordingly, deselection in HRM, will restrict the use and development of big data analytics and related tools until standards and norms for control in HRM are agreed.

\section{Algorithmic Responsibility and Accountability - Interests and Powers}

Algorithmic responsibility and accountability are required for several reasons, as discussed in the previous 'Application' section and in many of the chapters in this book. One important reason is that algorithms 
have no standing; only individuals and/or organizations have standing. Consequently, it is important to know who is responsible for the consequences of which algorithms, whether it is self-driving cars or medical treatments.

The issues of algorithmic responsibility and accountability are not primarily technical issues. The most important issues are interests, distribution of risks, profit, business concepts, privacy and ethics - all the big issues in society. Consequently, no objective criteria can be applied to define responsibility and accountability. The definitions of algorithmic responsibility and accountability depend on economic, social and political powers. As shown, particularly in Chapters 7 and 17, the biggest tech firms within social mass media are the key players in big data analytics and related tools. This begs the question: do these tech firms have an interest in becoming more responsible and accountable regarding their algorithms? Not really! On the other hand, if they do not, this may provoke conflicts between the tech firms and their customers, which may result in state regulations such as the new General Data Protection Regulation (GDPR) within the European Union. However, state regulations may take years to establish, as the case of GDPR shows. Therefore, in Chapter 7, Löfgren and Webster suggest agreements on certain minimum principles such as, among others, 'ethical standards regarding privacy and data protection. . . a clearer policy regarding the ownership of unstructured and structured data; and. . agreed standards regarding safety and protection of storing of data' as an alternative to state regulations.

\section{'Democratization' and Democracy}

One issue related to big data analytics and related tools is 'democratization'. The main argument here is that citizens can have access to big data and be provided with tools to process big data (see Chapter 16 and also Whelan, 2012). This scenario presents the possibility for citizens to have fair and just access to big data and not only be provided with big data literacy, but also practice the use of some of the tools in the data analysts' 'tool box'. However, Estivill-Castro writes in Chapter 2 that, for non-experts, it is not easy to interpret the results coming from the data analysts' 'tool box', and thus pick the most correct answers to the questions originally asked.

In addition, big data analytics and the related tools can be considered anti-democratic. The fear is that the aforementioned political communication in political campaigns, based on digital micro-marketing combined with other digital tools including fake news and disinformation, creates a situation of 'managed citizens' that results in a 'managerial democracy' that is less vibrant than the classic liberal democracy. The fear is that 
democracy is managed by the elites, which may provoke a 'revolt' against the elites by citizens who experience social, economic and political marginalization. Both arguments are presented, analysed and discussed in Chapter 16. Drawing on experiences from the USA, Aagaard concludes that the current balance between the two arguments leans towards anti-democratic.

\section{The Logic of Data - Dataism as a Super-recipe and an Institutionalized Logic!}

Big data analytics and the related tools install the logic of data as the key component in decision making and allocation of resources, as mentioned previously - that, is data, not humans, can tell which decisions are best to make and which allocation of resources is optimal. This belief in the logic of data, we term 'dataism'.

Dataism can be considered a super-recipe or a super-standard (Røvik, 2002). A super-recipe both diagnoses and cures an important managerial problem, according to Røvik (2002). Considered a super-recipe, according to its proponents, dataism provides both a diagnosis and a cure to nothing less than the problem of how to make the world a better place to live for most people. The provided diagnosis is that more insights are required to improve decision making and the allocation of resources, which is the solution because better decision making and allocation of resources mobilizes resources and consequently exploits the resources optimally.

First, more insights are required in energy, traffic, health, learning, pollution, and many more issues. Second, it is possible to improve decision making and the allocation of resources that promote more green energy based on more insights, better regulation of traffic in big cities, solutions to unsolved health issues, learning on the basis of digital feedback loops to improve education, and so on and so forth. Dataism can mobilize resources to promote the common good, which makes the world a better place to live for the most people.

Super-recipes such as dataism, new public management, LEAN management, and many more super-recipes are circulated worldwide by international consulting houses, international organizations such as the United Nations (UN), the Organisation for Economic Co-operation and Development (OECD) and academics. Super-recipes are circulated worldwide as semi-finished concepts, which must be turned into operational concepts within specific countries, fields and organizations to provide correct diagnoses and cures in daily operations (Røvik and Pettersen, 2014).

The risk of super-recipes, including dataism, is that correct diagnoses and treatments are not provided. This risk is considerable because superrecipes are promoted and implemented before there is conclusive evidence 
that they provide correct diagnoses and offer treatments that are effective (Røvik, 2002, pp. 120-21).

In Chapter 13, Sandgaard illustrates how the OECD has worked to define, design, conceptualize and promote big data governance in schools for years. The OECD claims that big data governance of schools, deployed by governments as a national management tool, increases efficiency in daily operations, uniform performances, and makes pupils experience higher grades and increased well-being.

The (policy) idea of big data governance of schools has been adopted by several welfare states, as presented in Chapter 13. One of these is the Danish welfare state, which is one of the most digitalized welfare states in the world. In Denmark and other countries, efforts have been made to transform the idea of big data governance of schools into a national concept. In Denmark, the ministry responsible for education provides the managers of the (primary) schools with data regarding the schools' performance, and the pupils' grades and well-being. The ministry sets goals for performance, grades and well-being. The managers feed national digital databases with data to make this more accurate. Finally, the managers are provided with digital tools to help them process the provided data from the ministry in order to make better decisions and allocation of resources, resulting in increased efficiency in daily operations, higher grades and increased well-being. However, research in both Denmark and other OECD countries shows that the provided tools are of very little help to school managers, who therefore often stick to pen and paper combined with selected data from the provided digital tools. In other words, it is difficult to translate the OECD's 'world of ideas' based on big data analytics and related tools to the school managers' 'world of practice'. Dataism is modified by practice; that is, combinations with other institutionalized logics.

Given the above, two scenarios are possible. First, dataism does not provide significantly better decision-making processes and allocation of resources. Dataism does not significantly mobilize individuals', organizations' and society's resources. In practice, dataism does not install the logic of data, including a digitalized version of the rational decision-making model. Dataism does not crowd out existing decision-making models and related models of resource allocation. Data analysts do not substitute for (semi-)professionals and experts as key employees in private and public organizations. If this scenario materializes, dataism will go down in history as a 'fashion' in the beginning of the twenty-first century. Second, dataism provides better decision-making processes and allocation of resources, and evolves into an institutional order - institutionalized logic - as defined within the meta-theory of the institutional logics perspective (Thornton et 
al., 2012). This includes that dataism does significantly mobilize individuals', organizations' and society's resources. In practice, dataism installs the logic of data, including a digitalized version of the rational decisionmaking model. Dataism crowds out existing decision-making models and related models of resource allocation. Data analysts do substitute for (semi-)professionals and experts as key employees in private and public organizations. If this scenario materializes, dataism will last long into the twenty-first century.

One of Thornton et al.'s (2012) key conclusions is that no institutionalized logic can fully dominate other institutionalized logics - market, profession, state, family, community, corporation and religion. Therefore, a kind of 'symbiotic co-existence' and 'symbiotic co-evolution' (Van Buuren et al., 2009, p. 158) of dataism and other institutionalized logics is most likely. However, a 'symbiotic co-existence' and 'symbiotic co-evolution' are not the end of conflicts among institutionalized logics. A stable equilibrium among the logics is not possible. All combinations of institutionalized logics involve conflicts, overlaps and competition according to the institutional logics perspective. On the other hand, combinations matter. Some combinations are destructive, meaning that divergence among logics is created. Other combinations are constructive, meaning that convergence among logics is created (Pedersen and Wilkinson, 2018). For advocates of dataism, the real challenge might be to combine dataism with other logics to create constructive 'symbiotic co-existence' and 'symbiotic co-evolution' that support a further development of dataism with the aim to tap big data from as many values as possible.

\section{CONCLUSION}

There is currently no grand theory that explains the development of big data analytics and the related tools: the core of the digital society. However, we know of some important elements - including the driving forces and the key players - and we can use our knowledge of other 'fashions' or super-recipes to predict outcomes. As with other fashions, more evidence about how managerial interests mould the system is required. The blindness of the prescriptive literature (in big data analytics and related tools as with many other management fashions) to issues of organizational power and behaviour means there is little understanding of the problems of implementation and the negotiation of outcomes. Resistance to dataism can be interpreted as something that can be overcome by means of education and leadership, as a problem related to people's natural tendency to avoid change, and there is no sense that this may also be a rational defence 
of interests. Dataism therefore appears to have the potential to become a source of conflict between competing interest groups and is not necessarily a force for unity (see Hill and Wilkinson, 1995 on this issue in relation to total quality management -TQM - a fashion of the 1990s). For example, dataism may be designed for economic efficiency but this may not be the most important consideration for a professional (Thornton et al., 2012, p. 73). This can result in differences in opinions and objectives for managers and professionals: "values about being economical or even efficient seldom loom large among the professionals, which can easily mean that what managers regard as a good result and what professionals strive to achieve are by no means the same thing' (Brunsson, 2009, p.62). Since there is limited empirical evidence regarding how dataism affects management in the literature, we can only speculate about processes and outcomes based on what seems plausible in light of knowledge about organizational behaviour in general.

We know of super-recipes/super-standards/master-ideas and some of the phases of the development of these and consequently of dataism (Røvik, 2002; Røvik and Pettersen, 2014). Benders and Van Veen (2001) referred to interpretive viability; that is, that the implementation of a concept or fashion might be loosely coupled with the original, and while widely used, it wears out over time as the practice or experience is rather different from what was promised. From this perspective, dataism may fade over time and be overtaken by new fashions.

A more positive view is that while digital society might not replace older-established models, there may be transposition (Thornton et al., 2012, p. 62); that is, elements from the different models and logics will be exchanged and models will be modified. From this perspective, there may be development as a 'symbiotic co-evolution' (Van Buuren et al., 2009) Accordingly, big data analytics and its related tools are likely to be the subject of debate related to its meaning and how it should be operationalized. A key issue is how the combinations of logics work. Specific combinations matter. Some combinations are destructive, meaning that divergence among logics is created, and other combinations are constructive, meaning that convergence among logics is created (Pedersen and Wilkinson, 2018). How the latter can be achieved is an interesting research question. We may see a dynamic and dialectic process (Strauss et al., 1964; McAuley, 1994) where members negotiate organizational realities through their different organizational and professional discourses, and while there may be fundamental tensions, we need to explore the more complex ways in which they coexist and interact (see Cohen et al., 2002). We hope this book contributes to the understanding of these processes. 


\section{REFERENCES}

Abrahamson, E. and G. Fairchild (1999), 'Management fashion: Lifecycles, triggers and collective learning processes', Administrative Science Quarterly, 44, $708-40$.

Batty, M. (2012), 'Smart cities, big data (editorial)', Environment and Planning B: Planning and Design, 39, 191-3.

Benders, J. and K. van Veen (2001), 'What's in a fashion? Interpretative viability and management fashions', Organization, 8(1), 33-53.

Binns, R. (2017), 'Algorithmic accountability and public reason', Philosophy and Technology, 31(4), 1-14.

Brunsson, N. (2009), Reform as Routine - Organizational Change and Stability in the Modern World, Oxford: Oxford University Press.

Cohen, L., R. Finn, A. Wilkinson and J. Arnold (2002), 'Professional work and management', International Studies of Management and Organization, 32(2), $3-24$.

Davenport, T.H. and D.J. Patil (2012), 'Data scientist: The sexiest job of the 21st century', Harvard Business Review, 90(5), 70-76.

Davidow, B. (2014), 'Algorithmic prison', The Atlantic, 20 February.

D'Ignazio, C. and R. Bhargava (2015), 'Approaches to big data literacy', paper presented at the Bloomberg Data for Good Exchange Conference, New York, 28 September.

Festinger, L. (1957), A Theory of Cognitive Dissonance, Evanston, IL: Row, Peterson \& Company.

Hill, S. and A. Wilkinson (1995), 'In search of TQM', Employee Relations, 17(3), $8-25$.

Kahneman, D. (2011), Thinking - Fast and Slow, New York: Farrar, Straus and Giroux.

Kahneman, D. and G. Klein (2009), 'Conditions for intuitive expertise', American Psychologist, 64(6), 515-26.

Lupton, D. (2015), Digital Sociology, London and New York: Routledge and Taylor \& Francis Group.

March, J.G. (1995), Fornuft og Forandring [Reason and Change] (a collection of March's most influential articles), Copenhagen: Samfundslitteratur.

March, J.G. (1998), 'Myths of management', talk at l'École de Paris, 28 May.

Marchington, M., A. Wilkinson, P. Ackers and J. Goodman (1993), 'The influence of managerial relations on waves of employee involvement', British Journal of Industrial Relations, 31(4), 553-76.

McAuley, J. (1994), 'Exploring issues in culture and competence', Human Relations, 47, 417-30.

Morrell, K. and M. Learmouth (2017), 'Evidence based management', in A. Wilkinson, S. Armstrong and M. Lounsbury (eds), The Oxford Handbook of Management, Oxford: Oxford University Press.

Pedersen, J.S. (2010), 'Reformer i den offentlige sektor - skab seks plusser' [Public Sector Reforms in Denmark], Copenhagen: Jurist- og Økonomforbundets Forlag.

Pedersen, J.S. and A. Wilkinson (2018), 'The digital society and provision of welfare services', International Journal of Sociology and Social Policy, 38(3/4), 194-209. 
Rousseau, D.M. and E.G.R. Barends (2011), 'Becoming an evidence-based HR practitioner', Human Resource Management Journal, 21, 221-35.

Røvik, K.A. (2002), 'The secrets of the winners: Management ideas that flow', in K. Sahlin-Anderson and L. Engwall (eds), The Expansion of Management Knowledge: Carriers, Flows and Sources, Stanford, CA: Stanford Business Books, pp. 113-44.

Røvik, K.A. and H.M. Pettersen (2014), 'Masterideer' [Master-ideas], in K.A. Røvik, E.M. Furu and T.V. Eilertsen (eds), Reformideer i norsk skole: Spredning, oversettelse og implementering, Oslo: Cappelen Damm Akademisk.

Strauss, A.L., L. Schatzman, R. Bucker, D. Ehrlich and M. Sabshin (1964), Psychiatric Institutions and Ideologies, New York: Free Press.

Thornton, P., W. Ocasio and M. Lounsbury (2012), The Institutional Logics Perspective: A New Approach to Culture, Structure and Process, Oxford: Oxford University Press.

USACM (2017), 'Statement on algorithmic transparency and accountability', US Association for Computing Machinery Public US Policy Council, 12 January, accessed September 2017 at https://www.acm.org/binaries/content/assets/publicpolicy/2017_usacm_statement_algorithms.pdf.

Van Buuren, A., L. Gerrits and P. Marks (2009). 'Public policy-making and the management of coevolution', in G. Teisman, A. van Buuren and L. Gerrits (eds), Managing Complex Governance Systems: Dynamics, Self-Organization and Coevolution in Public Investment, New York: Routledge, pp. 154-71.

Whelan, C. (2012), Big Data and the Democratisation of Decisions, Economist Intelligence Unit report.

Wilkinson, A. and P. Mowbray (2019), 'Creating and sustaining involvement and participation in the workplace', in A. Wilkinson, N. Bacon, T. Redman and S. Snell (eds), The SAGE Handbook of Human Resource Management, London: SAGE.

Wilkinson, A., S. Armstrong and M. Lounsbury (2017), The Oxford Handbook of Management, Oxford: Oxford University Press.

Winter, S. and P.E. Mouritzen (2001), 'Why people want something for nothing: The role of asymmetrical illusions', European Journal of Political Research, 39(1), 109-43. 